ORIGINAL ARTICLE

\title{
Comparison of High-sensitivity C-reactive Protein Level between Chronic Kidney Disease Stages
}

\author{
Tri Asih Imro'ati' ${ }^{1}$, Mochammad Thaha ${ }^{2 *}$, Aditiawardana², Widodo², Pranawa ${ }^{2}$, Chandra \\ Irwanadi $^{2}$
}

${ }^{1}$ Department of Internal Medicine, Faculty of Medicine, Universitas Airlangga - Dr. Soetomo General Hospital, Surabaya ${ }^{2}$ Nephrology Division, Department of Internal Medicine, Faculty of Medicine, Universitas Airlangga - Dr. Soetomo General Hospital, Surabaya

\author{
A R T I C L E I N F O \\ Article history: \\ Received 1 Mei 2018 \\ Received in revised form 17 Mei 2018 \\ Accepted 30 Mei 2018 \\ Available online 30 April 2018 \\ Keywords: \\ chronic kidney disease \\ high sensitivity C- Reactive Protein. \\ *) Corresponding author: \\ mochthaha@yahoo.com
}

\begin{abstract}
A B S T RA C T
Introduction: This research is to evaluate the hs-CRP level comparison between CKD stages in Dr. Soetomo General Hospital Surabaya.

Methods: An analytic observational cross-sectional study, evaluating the differences of hsCRP level between CKD stages in 72 patients with CKD (mean age 55.49 \pm 7.62 years, the ratio between male:female was 1:1.48, mean BMI $24.18 \pm 3.64 \mathrm{~kg} / \mathrm{m} 2,36.11 \%$ diabetics, $43.05 \%$ on ACEI/ARB, $29.16 \%$ on statin), recruited from Nephrology Outpatient Clinic, Dr Soetomo General Hospital, Surabaya, from January to May 2014. The stages were stratified according to the MDRD formula.

Results: The mean hs-CRP of CKD stage 3 was $2.29 \pm 2.86$, stage 4 was $2.48 \pm 2.19$, and non-dialysis stage 5 was $2.09 \pm 2.54$. The analysis using Kruskal-Wallis test showed no significant differences among patients with CKD stage 3, stage 4, and non-dialysis stage 5 (median 1.25 vs 1.80 vs $1.05 \mathrm{mg} / \mathrm{L}$; $\mathrm{p}=0.430$ ). No significant differences of the serum hsCRP level were detected between diabetics and non diabetics in stage 3, 4, and non-dialysis stage $5 \quad(p=0.673$ vs 0.666 vs 0.138$)$; between patients with and without ACEI/ARB treatment $(\mathrm{p}=0.610$ vs 0.649 vs 0.671 ); and between patients with and without statin treatment ( $\mathrm{p}=0.852$ vs 0.341 vs 0.309$)$.

Conclusion: There was no difference of serum hs-CRP between CKD stages. The elevation of serum hs-CRP level can not indicate the decline of kidney function, but it still needs further investigations.
\end{abstract}

\section{Introduction}

Chronic kidney disease is a major public health problem in both developed and developing countries, whose number is increasing from year to year. ${ }^{1}$ It can be identified from the diagnosis of CKD in Dr. Soetomo Hospital, which increased from 332 cases in 2008 to 4535 cases in 2012. Number of Hemodialysis Installation visit also increased from 7590 cases in 2008 to 23811 cases in $2012 .^{2}$
Chronic kidney disease is a irreversible and progressive disease. ${ }^{3}$ The decline in CKD progress may reduce the load of the limited number of dialysis machines, and reduce the cost of CKD hospitality since it is not covered by the insurance. Chronic kidney disease is associated with inflammatory processes, and its progressiveness is associated with undergoing chronic inflammatory process. ${ }^{4,5}$ The process begins with the injury in the kidney that activates immune system and

Biomolecular and Health Science Journal

Available at https://e-journal.unair.ac.id/BHSJ ; DOI: 10.20473/bhsj.v1i1.8226 
repair mechanisms of injury in cells or tissues. However, the process does not cease, and tends to become a chronic inflammatory process that is characterized by kidney tissue matrix changes from one stage to another until the formation of fibrotic tissue that affects kidney function. ${ }^{3,6,7}$

Various conditions on the CKD (such as damaged nephron hypoperfusion, increasing renin, angiotensin, aldosterone, reduction of erythropoietin, vitamin $\mathrm{D}$, uromodulin and protein catabolism; uremia and retention of metabolic waste, as well as extensive proteinuria) can stimulate systemic inflammation through the process of chronic oxidative stress, immune dysregulation and calcium and bone loss, intestinal barrier dysfunction and endotoxemia, as well as decreased cytokines elimination. Inflammatory markers, such as IL-6 and CRP, are associated with CKD. Chronic activation of immune system in uremia causes low-grade chronic inflammation. The term 'uremia' itself indicates ill state in renal failure, especially due to retention of substances that are normally removed by the kidneys. Persistent inflammation is a risk factor of CKD progress, thereby inflammation reduction is very significant in the treatment of kidney disease. . $^{3,6,7}$

Chronic inflammation and its association with poor outcomes in CKD is not new, but many clinicians and researchers are still keen to examine the inflammatory markers in renal disease. ${ }^{5}$ Clinical use by monitoring CRP levels in patients with CKD, especially in final stage, is getting closer to reality, while the use of CRP for evaluation and therapy is still being adjusted case by case ${ }^{8} \mathrm{C}$-reactive protein (CRP) is a most frequently used inflammation marker. C-reactive protein does not show a significant circadian variability in stable condition, and its stability in laboratory measurements is comparable to serum cholesterol levels. These characteristics make CRP a reliable marker of inflammation. ${ }^{8}$

Several factors that can affect CRP levels are diabetes, infection, smoking, chronic diseases, sleep disorders, malnutrition, anemia, old age, alcohol consumption, CVD, hypertension, vascular access, pregnancy, pharmacological therapy, dialysis and CRP gene polymorphism. ${ }^{8,9,10,11}$ Research reports on the degree of inflammation (indicated by elevated levels of CRP) and its relation to CKD stages is still not available in Indonesia. Studies to identify high risk patients who have experienced a worsening of CKD based on inflammatory level are needed. It remains to be investigated whether CRP levels differ at each stage of CKD.

This study was intended to determine the difference of hs-CRP levels in patients with CKD stage 3, 4, and 5 non-dialysis treated at the Kidney-Hypertension Outpatient Clinic, Department of Internal Medicine, Dr. Soetomo Hospital. Selection of studied stage was based on the results of preliminary study conducted in December 2013 in which the most-common stage was stage $3(36.74 \%), 4(36.69 \%)$ and 5 (18.37\%) nondialysis.

\section{Methods}

This was a comparative numerical analytic observational study using cross-sectional design. The study was conducted at the Kidney-Hypertension Outpatient Clinic, Dr. Soetomo Hospital, from January to May, 2014. The population studied were all patients with CKD who were treated at Kidney-Hypertension Outpatient Clinic, Dr. Soetomo Hospital. The samples studied were patients with CKD stage 3, 4, and 5 non-dialysis. The sample size of each group was 21 (CKD stage 3 were 21 , stage 4 were 21 , non-dialysis stage 5 were 21 patients). To anticipate subject loss, data loss, and damaged sample, the studied subjects were added as many as $10 \%$, so that the number of subjects became 24 patients, bringing the total sample to 72 samples. Sampling technique used a quota sampling method.

Criteria for inclusion in this study were that the subjects agreed to participate in the study, patients with CKD stage 3, 4, and 5 non-dialysis who visited KidneyHypertension Outpatient Clinic, Dr. Soetomo Hospital, aged 21-65 years, and the subjects were able to do autoanamnesis. The exclusion criteria in this study were that the subjects were in a state of hemodynamic instability, the subjects have been undergoing dialysis, experienced edema, having uncontrolled diabetes, suffering from coronary heart disease, on hormone replacement therapy, had TDS > $160 \mathrm{mmHg}$, active smokers, alcohol drinkers, having sleep disorders, having infection, $\mathrm{Hb}<8 \mathrm{~g} / \mathrm{dl}$, having obesity, having a history of vascular access other than AV shunt, and suffering from chronic diseases in addition to CKD.

This study obtained data from clinical history and medical records of patients with CKD stage 3, stage 4 and non-dialysis stage 5. Blood pressure was measured using a standardized digital tensimeter (Acon). Body weight was measured using standardized digital scale (SMIC). Height was measured using standardized measuring instrument (SMIC). Axillary body temperature was measured using a digital thermometer (Omron). Laboratory data were obtained from venous blood tests performed by the laboratory PT. Prodia Widyahusada Surabaya. All data were recorded in the patient's record sheet.

Data were analyzed with descriptive statistics and presented in frequency distribution tables and diagrams. Statistical analysis of the differences between the three groups of test subjects was done by one way Anova when the normal distribution of data, or the Kruskal Wallis test when the data distribution was not normal, using SPSS version 17.0 (student version). 


\section{Results}

The total number of samples in this study were 72 patients with CKD undergoing outpatient treatment at Kidney-Hypertension Clinic, Dr. Soetomo Hospital, who met the inclusion and exclusion criteria, and divided into three groups consisting of 24 patients with stage 3, 24 patients with stage 4 , and 24 patients with non-dialysis stage 5 .

Table 1. General characteristics of the patients

\begin{tabular}{|c|c|c|c|c|}
\hline Characteristics & Stage 3 & Stage 4 & $\begin{array}{c}\text { Stage } 5 \\
\text { nondialysis }\end{array}$ & $P^{*}$ \\
\hline \multicolumn{5}{|l|}{ Age (years) } \\
\hline Mean \pm SD & $56.88 \pm 5.38$ & $54.83 \pm 7.29$ & $54.75 \pm 9.70$ & 0.556 \\
\hline Range & $46-65$ & $40-65$ & $28-64$ & \\
\hline \multicolumn{5}{|l|}{ Gender: } \\
\hline Male & $15(62.5 \%)$ & $7(33.3 \%)$ & $7(33.3 \%)$ & \\
\hline Female & $9(37.5 \%)$ & $17(66.7 \%)$ & $17(66.7 \%)$ & \\
\hline \multicolumn{5}{|l|}{ DM: } \\
\hline DM Controlled & $6(25.0 \%)$ & $10(41.7 \%)$ & $10(41.7 \%)$ & \\
\hline Non DM & $18(75.0 \%)$ & $14(58.3 \%)$ & $14(58.3 \%)$ & \\
\hline \multicolumn{5}{|l|}{ Hypertension: } \\
\hline ACEI/ARB therapy & $8(33.3 \%)$ & $11(45.8 \%)$ & $12(50.0 \%)$ & \\
\hline Non HT/non ACEI/ARB & $16(66.7 \%)$ & $13(54.2 \%)$ & $12(50.0 \%)$ & \\
\hline \multicolumn{5}{|l|}{ Dyslipidemia: } \\
\hline Statin therapy & $7(29.2 \%)$ & $10(41.7 \%)$ & $4(16.7 \%)$ & \\
\hline Non-dyslipidemia/non statin & $17(70.8 \%)$ & $14(58.3 \%)$ & $20(83.3 \%)$ & \\
\hline
\end{tabular}

Source: research data, processed

* comparison between groups

Table 2. Specific characteristics of the patients

\begin{tabular}{|c|c|c|c|c|c|c|c|}
\hline \multirow[t]{2}{*}{ Parameter } & \multicolumn{2}{|c|}{ Stage 3} & \multicolumn{2}{|c|}{ Stage 4} & \multicolumn{2}{|c|}{ Stage 5 nondialisis } & \multirow[b]{2}{*}{$P^{*}$} \\
\hline & Mean \pm SD & Range & Mean \pm SD & Range & Mean \pm SD & Range & \\
\hline \multicolumn{8}{|l|}{ CKD: } \\
\hline Hemoglobin & $12.97 \pm 1.99$ & $9.94-16.50$ & $11.33 \pm 2.06$ & $8.03-16.00$ & $10.11 \pm 1.53$ & $8.02-13.10$ & $<0.001$ \\
\hline $\begin{array}{l}\text { Serum } \\
\text { kreatinin }\end{array}$ & $1.73 \pm 0.34$ & $1.20-2.40$ & $2.70 \pm 0.50$ & $1.80-3.70$ & $5.58 \pm 2.59$ & $3.30-15.50$ & $<0.001$ \\
\hline $\begin{array}{l}\text { Estimated } \\
\text { LFG }\end{array}$ & $40.21 \pm 7.59$ & $30.14-58.25$ & $22.16 \pm 3.91$ & $16.46-29.97$ & $10.80 \pm 3.01$ & $2.89-15.00$ & $<0.001$ \\
\hline Calcium & $9.18 \pm 0.44$ & $8.20-10.40$ & $8.78 \pm 0.36$ & $7.90-9.40$ & $8.55 \pm 0.58$ & $7.40-9.70$ & $<0.001$ \\
\hline Phosphate & $3.38 \pm 0.60$ & $2.40-4.40$ & $3.81 \pm 0.74$ & $2.40-5.40$ & $4.20 \pm 0.81$ & $2.90-6.20$ & 0.001 \\
\hline \multicolumn{8}{|l|}{ Malnutrisi: } \\
\hline BMI & $24.32 \pm 3.02$ & $18.30-29.00$ & $23.89 \pm 4.08$ & $15.60-30.70$ & $24.33 \pm 3.88$ & $15.53-31.14$ & 0.897 \\
\hline Albumin & $4.56 \pm 0.33$ & $4.00-5.20$ & $4.29 \pm 0.46$ & $3.10-5.10$ & $4.10 \pm 0.50$ & $2.90-5.10$ & 0.002 \\
\hline \multicolumn{8}{|l|}{$\begin{array}{l}\text { Blood } \\
\text { pressure: }\end{array}$} \\
\hline Systolic & $135.50 \pm 13.59$ & $104-160$ & $133.12 \pm 17.43$ & $103-160$ & $140.04 \pm 15.37$ & $110-160$ & 0.299 \\
\hline Diastolic & $80.71 \pm 8.64$ & $62-94$ & $73.96 \pm 12.85$ & $47-95$ & $75.46 \pm 13.16$ & $52-100$ & 0.120 \\
\hline \multicolumn{8}{|l|}{ Dyslipidemia: } \\
\hline Triglyceride & $157.08 \pm 104.12$ & $61-499$ & $144.63 \pm 63.20$ & $57-325$ & $127.21 \pm 52.29$ & $35-257$ & 0.402 \\
\hline $\begin{array}{l}\text { Total } \\
\text { cholesterol }\end{array}$ & $185.29 \pm 33.17$ & $144-280$ & $188.46 \pm 43.99$ & $120-302$ & $168.21 \pm 37.22$ & $72-234$ & 0.153 \\
\hline LDL & $103.21 \pm 28.94$ & $45-196$ & $108.79 \pm 30.08$ & $51-165$ & $93.92 \pm 28.67$ & $33-146$ & 0.212 \\
\hline HDL & $45.63 \pm 14.19$ & $21-72$ & $46.79 \pm 13.52$ & $32-91$ & $47.08 \pm 19.17$ & $25-124$ & 0.945 \\
\hline $\begin{array}{l}\text { Insulin } \\
\text { resistance: } \\
\text { GDA }\end{array}$ & $110.75 \pm 34.91$ & $75-224$ & $109.04 \pm 29.50$ & $76-216$ & $117.96 \pm 32.05$ & $77-189$ & 0.598 \\
\hline \multicolumn{8}{|l|}{$\begin{array}{l}\text { Liver } \\
\text { disorder: }\end{array}$} \\
\hline SGOT & $23.75 \pm 9.91$ & $13-59$ & $20.54 \pm 5.71$ & $14-40$ & $22.13 \pm 12.01$ & $9-67$ & 0.513 \\
\hline SGPT & $26.08 \pm 11.91$ & $10-69$ & $22.71 \pm 8.43$ & $8-45$ & $24.25 \pm 16.79$ & $9-80$ & 0.662 \\
\hline \multicolumn{8}{|l|}{$\begin{array}{l}\text { CRP- } \\
\text { stimulating } \\
\text { cytokine: }\end{array}$} \\
\hline
\end{tabular}

Source: Research Data, Processed

* comparison between groups 
Age characteristics of patients with CKD stage 3, stage 4 and stage 5 non-dialysis generally showed that the mean obtained was not significantly different $(\mathrm{p}=$ $0,556)$, which was in the range of 54.75 to 56.88 years. The youngest age of the patients with CKD was 28 years (non-dialysis stage 5 ) and the oldest 65 years old. It could be concluded that the ages of patients with CKD who became samples from stage 3 to stage 5 nondialysis were homogeneous because the standard deviation was relatively small. Gender for patients with CKD stages 3 was predominantly male with a percentage of $62.5 \%$ of 24 patients. Patients with CKD stage 4 and stage 5 non-dialysis were mostly female with respective percentages of $66.7 \%$.

Patients with diabetes mellitus (DM) included in this study were patients with DM already controlled by medication or insulin. In the stage 3 group there were $25 \%$, whereas in stage 4 and 5 non-dialysis the number was the same, $41.7 \%$. Most non-DM CKD patients were seen in group stage $3(75 \%)$, while the other two groups was $58.3 \%$. Hypertensive patients using ACEI/ARB were at least found in group stage $3(33.3 \%)$, while the most were found in non-dialysis stage $5(50 \%)$. Patients with dyslipidemia using statins were mostly in group stage $4(41.7 \%)$, while the least were present in patients with non-dialysis stage $5(16.7 \%)$.

Special characters were divided into several parameters that could affect the level of hs-CRP, such as factors present in CKD (identified from hemoglobin, serum creatinine, estimated LFG, calcium and phosphate), malnutrition (identified from BMI and albumin), blood pressure, dyslipidemia, insulin resistance (identified from GDA), impaired liver function (identified from SGOT and SGPT), and a cytokine that stimulated the formation of CRP, the HSIL-6. Thus, it could be ascertained that this study had excluded of some of those confounding variables (Table 2).

The description of the data for the parameters of hemoglobin, creatinine clearance, Calcium and Albumin, in general could lead to the conclusion that the higher the stage of CKD patients, the lower the mean value. This indicates that the increase the stage of patients with CKD stage, the higher the tendency to lose the characteristics.

Specific criteria such as Serum creatinine and phosphate in every stage is increasing along with increasing stage of CKD experienced by the patient. This indicates that along with the increasing stage of patients with CKD, the tendency to increase special characteristics of serum creatinine phosphate in those patients is also increasing. Other special characteristics, the blood sugar, SGOT and SGPT, also have the same tendency, in which in stage 4 the mean value was relatively lower than those in non-dialysis stage 3 and stage 5. Total cholesterol and LDL had different inclination from the characteristics of blood sugar,
SGOT and SGPT where in stage 4 the mean value was much higher than those in stage 3 and stage 5 nondialysis.

The value of Body Mass Index (BMI) generally has a mean that is not remarkably different $(\mathrm{p}=0.897)$, which is in the range of 23.89 to 24.33. Lowest BMI value of the 72 patients (all groups of samples) was 15.53 and the highest was 31.14. Highest mean of hs-IL6 level was present in stage 4 , followed by stage 3 , and the lowest was in stage 5 non-dialysis, but overall there was no significant differences between groups of samples $(\mathrm{p}=0.574)$.

Some special characteristics that have been described, despite having a different inclination, increasing or decreasing and the sometimes fluctuative with increasing stages of CKD suffered by patients, in general had relatively homogeneous distribution. This condition was indicated by the standard deviation between each stage that was lower than the average obtained, except for the variable hs-IL-6 that had no normal distribution.

\section{hs-CRP Level in Each CKD Groups}

The result of description of hs-CRP values in 72 patients with CKD wre grouped into 24 patients with stage 3, 24 patients with stage 4 and 24 patients with stage 5 nondialysis (Table 3).

Table 3. Levels of hs-CRP among patients between CKD stages

\begin{tabular}{lccc}
\hline \multicolumn{1}{c}{ Parameters } & \multicolumn{3}{c}{ Statistics } \\
\cline { 2 - 4 } & Mean \pm & Range & Median \\
& SD & & \\
\hline hs-CRP (Stage 3) & $2.29 \pm$ & $0.20-$ & 1.250 \\
& 2.86 & 11.60 & \\
hs-CRP (Stage 4) & $2.48 \pm$ & $0.30-$ & 1.800 \\
& 2.19 & 9.30 & \\
hs-CRP (Stage 5 & $2.09 \pm$ & $0.40-$ & 1.050 \\
nondialysis) & 2.54 & 9.80 & \\
\hline
\end{tabular}

Source: research data, processed

Results of hs-CRP data description according to the stage of CKD revealed that highest mean value of hsCRP showed the highest in CKD stage 4 of to $2.48 \mathrm{mg} / \mathrm{L}$ compared with CKD stage 3 and stage 5 non-dialysis. The lowest value of hs-CRP was found in CKD stage 5 non-dialysis of $2.09 \mathrm{mg} / \mathrm{L}$. CKD stage 3 had a tendency of greater diversity than CKD stage 4 and 5 non-dialysis, as seen at the data range of hs-CRP in patients with stage 3 which was between $0.20 \mathrm{mg} / \mathrm{L}$ to $11.60 \mathrm{mg} / \mathrm{L}$. 


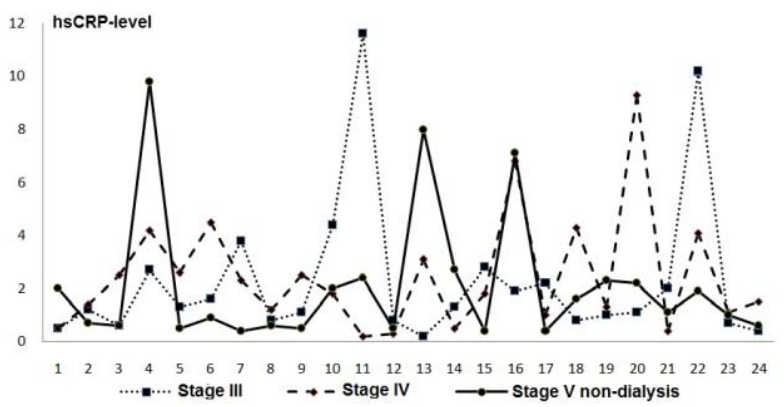

Figure 1. Distribution of hs-CRP data on the three CKD stages

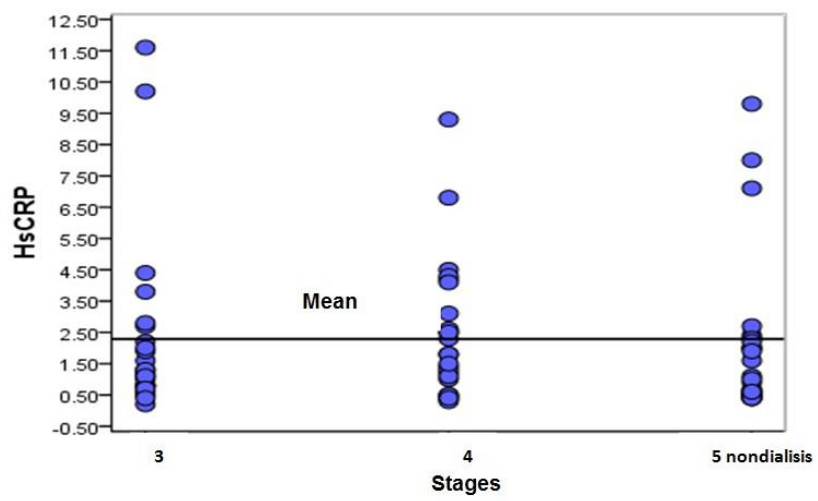

Figure 2. hs-CRP data scatter along with the trend of the average values

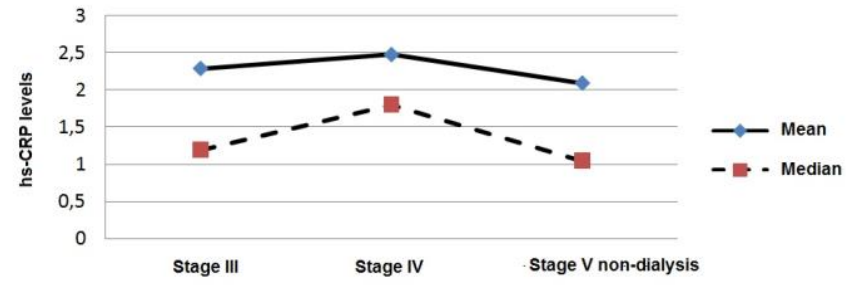

Figure 3. Mean and median of hs-CRP on the three CKD stages

\section{Comparison of hs-CRP Level between CKD Stages}

Comparative testing of hs-CRP levels in 72 patients based on the degree of CKD was done by using One Way Anova for hs-CRP data with normal distribution and the Kruskal Wallis test if hs-CRP data was not normally distributed although transformation had been done to the respective hs-CRP data. In addition to data normality test, assumption that must be met by One Way Anova was the homogeneity of variance test data performed by with Levene Test method.

Test results of h-sCRP normality with the ShapiroWilk method indicated that the data 24 of hs-CRP in the three stages of CKD did not spread by normal distribution. hs-CRP data in three stages spread substantially with positive skewness. The recommended type of data transformation based on the book Ghozali (2006) was logarithmic transformation (Lg10).

The results of data normality of test with ShapiroWilk method after transformation with logarithm ion hsCRP data obtained p-value of 0.733 (Stage 3), 0,559 (Stage 4) and 0.028 (non-dialysis Stage 5) all of which were not higher than the significance level of $0.05(5 \%)$ the Log hs-CRP of non-dialysis stage 5. It could be concluded that the distribution of 24 data of Log-hs-CRP in three CKD stages did not spread by normal distribution. Thus, the comparative test of hs-CRP the three CKD stages would be conducted using Kruskal Wallis non-parametric statistics test using the median value of the data that had been subjected to transformation. The results of Kruskal Wallis test is presented in Table 4.

Table 4. Results of the Kruskal-Wallis test of hs-CRP

\begin{tabular}{lccc}
\hline \multicolumn{1}{c}{ Variables } & $\begin{array}{c}\text { Median } \\
\text { hs-CRP }\end{array}$ & $\begin{array}{c}\text { p-value } \\
\text { Kruskal- } \\
\text { Wallis }\end{array}$ & Notes \\
\hline hs-CRP Stage 3 & 1.250 & 0.430 & Not \\
hs-CRP Stage 4 & 1.800 & & Significantly \\
hs-CRP Stage 5 & 1.050 & & Different \\
nondialysis & & & \\
\hline
\end{tabular}

Source: Research Data, Processed

This study also analyzed the comparison of hs-CRP at each stage of CKD based on the presence or absence of diabetes mellitus, the use of ACEI/ARB and statin use, because it could not exclude the three factors that affect the levels of hs-CRP. The number of samples for each group was relatively small $(<20)$ so it was decided to use a non-parametric statistical test of Mann Whitney U Test (Table 5).

Table 5. Results of the comparative test of hs-CRP

\begin{tabular}{|c|c|c|c|}
\hline Variables & Based On & $\begin{array}{c}\text { p-value } \\
\text { Mann } \\
\text { Whitney }\end{array}$ & Notes \\
\hline \multirow[t]{3}{*}{ hs-CRP Stage 3} & DM & 0.673 & $\begin{array}{c}\text { Not Significantly } \\
\text { Different }\end{array}$ \\
\hline & ACEI/ARB & 0.610 & $\begin{array}{c}\text { Not Significantly } \\
\text { Different }\end{array}$ \\
\hline & Statin & 0.852 & $\begin{array}{c}\text { Not Significantly } \\
\text { Different }\end{array}$ \\
\hline \multirow[t]{3}{*}{ hs-CRP Stage 4} & DM & 0.666 & $\begin{array}{c}\text { Not Significantly } \\
\text { Different }\end{array}$ \\
\hline & ACEI/ARB & 0.649 & $\begin{array}{c}\text { Not Significantly } \\
\text { Different }\end{array}$ \\
\hline & Statin & 0.341 & $\begin{array}{c}\text { Not Significantly } \\
\text { Different }\end{array}$ \\
\hline hs-CRP Stage 5 & DM & 0.138 & $\begin{array}{c}\text { Not Significantly } \\
\text { Different }\end{array}$ \\
\hline non dialysis & ACEI/ARB & 0.671 & $\begin{array}{c}\text { Not Significantly } \\
\text { Different }\end{array}$ \\
\hline
\end{tabular}




\section{Statin $\quad 0.309 \quad$ Not Significantly Different}

Source: research data, processed

The results of comparative test of hs-CRP levels in non-dialysis stage $5 \mathrm{CKD}$ based on whether there was any indication of diabetes mellitus, the use of ACEI/ARB and the use of statins produced $p$-value of $0.138 ; 0.671$ and 0.309 , which were higherthan 0.05 $(5 \%)$. Thus, it was concluded that hs-CRP in non-dialysis stage 5 based on DM, ACEI/ARB and statins was also not significantly difference.

\section{Discussion}

\section{Characteristics of Research Subjects}

Comparative research report on hs-CRP levels between the stages of CKD have not been obtained in Indonesia. However, there are few studies of hs-CRP in patients with CKD, either receiving predialysis and routine dialysis ,that could be used as a comparison. This study used patients with stage 3,4 and 5 non-dialysis because of the data from preliminary study conducted in December 2013 revealed that CKD stages distribution was highest on those stages with successive presentations of $36.74 \%, 36.69 \%$, and $18.37 \%$. This study did not include stage 1 and 2 because of the preliminary study found small presentation (10.2\%) that will cause its own difficulties in collecting the number of samples within a limited time.

In this study, the mean age of the study subjects were almost the same when compared to some previous studies Fox et al. (2010), Abraham et al. (2009), Romao et al. (2006), and Pecoits-Filho et al. (2003). This study did not include age over 65 years because of hs-CRP levels tend to increase with age. ${ }^{15}$

Comparison of study subjects revealed more men on stage 3 and more women on stage 4 and 5 nondialysis. Total ratio of men than women in this study was 1: 1.48, in line with the studies by Fox et al. (2010), Romao et al. (2006), and Pecoits-Filho et al. (2003), where the number of female patients was higher than males, with a ratio of respectively $1: 1.71 ; 1: 1.17$; and 1 : 1.84 .

Gender affects the incidence, prevalence and progression of kidney disease. Men are more progressive than women in systemic disease that causes kidney failure. Several factors play a role in this case, namely the diet, size of glomerular and kidney, hemodynamic differences and direct effects of sex hormones, in which estrogen will slow the speed of progression by inhibiting the inflammatory processes and apoptosis, as well as protecting kidney tissue. ${ }^{16,17}$ In this study, it appears that in stage 3 the number of male patients was higher, while at stage 4 and stage 5 more there were more female patients.
Diabetes mellitus, hypertension, use of ACEI/ARB, dyslipidemia and statins also can affect CRP levels. ${ }^{8,9,10,11,15,18}$ This study could not exclude some of the factors that could affect the hs-CRP levels due to the limited sampling time. In this study, controlling the confounding factors of hs-CRP result has been considered, for example, blood sugar, antihypertensive and statin use. These factors have been reported to affect the levels of hs-CRP. Studies by Pecoits-Filho et al. (2003), Romao et al. (2006), Abraham et al. (2009), and Fox et al. (2010) reported that a rise in blood sugar levels can affect CRP. Number of patients with DM were included in the study respectively $27 \%, 40 \%, 59 \%$, and $13.7-18.9 \%$, whereas in this study $36.11 \%$.

A study by Fox et al. (2010) also reported that the use of antihypertensives (46.8\%) and statins (12\%) can affect CRP because hypertension can cause endothelial stress which in turn induces low grade inflammation, while ACEI, ARB, and CCB are associated to decreased levels of inflammatory mediators of blood circulation in patients with hypertension, diabetes mellitus and nonDM. ${ }^{8,15,19}$ The use of statins, a HMG CoA reductase inhibitors, can lower CRP levels, regardless of the effect on the lipid profile with a mechanism that is still unknown whether it has direct effect on hepatocytes, as an anti-inflammatory in atherosclerotic plaques, and/or other anti-inflammatory effects. ${ }^{8,15,16}$ In this study the use of antihypertensives and statins was $43.05 \%$ and $29.16 \%$.

Metabolic factors due to uremia are strongly influenced by the stage of CKD. Results of this study found that hemoglobin, serum creatinine, GFR estimates, the level of calcium, phosphate, and albumin are uremia metabolic factors that correspond to the stage. $\mathrm{Hb}$ decrease in CKD is due to: 1) a decrease in the production of erythropoietin by the kidney, leading to decreased production of red blood cells in the bone marrow, and anemia that causes hypoxia; 2) hypoxia will increase hepsidin that causes functional iron deficiency through inhibition of iron absorption in the intestine and inhibition of Fe distribution in blood circulation as more is stored in macrophages or spleen; 3) uremia associated inflammation will lead to anemia which can lead to later chronic oxidative stress inducing systemic inflammation that causes more severe anemia and become an unbroken chain. ${ }^{6,7,21,22}$ In this study, the higher the stage, the lower the mean $\mathrm{Hb}$ (range 8.02 to $16.5 \mathrm{~g} / \mathrm{dl}$ ), not much different from a result of study research Leeder et al. (2005) in which the Hb levels in CKD ranges between 7.6 to $14.6 \mathrm{~g} / \mathrm{dl}$.

Kidney is the organ of calcium and phosphate regulation. Decreased calcium in CKD is caused by: 1) the synthesis of active vitamin D (calcitriol) decreases because uremia stimulates FGF23 conditions; 2) fibroblast growth factor 23 (FGF23) regulates the excretion and reabsorption of phosphate and reduce calcitriol production; 3) increased levels of phosphate triggers mobilization of calcium deposits in bones into 
the peripheral; 4) the release of parathyroid hormone due to increased phosphate to maintain the balance of calcium and phosphate. ${ }^{7,24}$ In this study, the higher the stage, the lower the mean calcium levels and, conversely, the higher the phosphate levels. In a study by Ketteler et al. (2008) the mean phosphate level in predialysis patients was $6.2 \pm 0.8 \mathrm{mg} / \mathrm{dl}$, higher than this study.

Decreased levels of albumin in patients with CKD can be caused by: 1) low intake of protein; 2) resistance of insulin anabolic effects; 3 ) other hormones; 4) growth factor; 5) metabolic acidosis and activation of inflammatory cytokines that stimulate protein breakdown; 6) increase in blood pressure and nephropathy in diabetes can increase proteinuria which also results in lower levels of albumin in the blood. ${ }^{26} \mathrm{In}$ this study, the higher the stage, the lower the mean albumin levels. Research by Abraham et al. (2009) and Pecoits-Filho et al. (2003) also supports this finding, with a mean of $3.2 \pm 0.7$ and $3.3 \pm 0.04$, lower than the results of this study. This study excluded BMI of more or less than normal, as well as blood pressure, lipid profile, and transaminase that have also been evaluated as they can affect CRP levels.

Obesity is a condition of low-grade systemic inflammation, a major factor that affects CRP levels because fatty tissue expresses and releases proinflammatory cytokines, particularly IL-6. ${ }^{27,28}$

In this study, obese patients were not found, so was in the studies by Abraham et al. (2009) and Pecoits-Filho et al. (2003). A study by Fox et al. (2010) reported that obesity increases CRP levels (BMI at the lower 75th percentile of CRP $<5.7 \mathrm{mg} / \mathrm{L}$ of $30.3 \pm 6.1$ and in the upper 25th percentile of CRP ? $5.7 \mathrm{mg} / \mathrm{L}$ of $36.1 \pm 8,3$ ).

Increased blood pressure in CKD is due to: 1) increased levels of renin, angiotensin and aldosterone as a result of hypoperfusion nephrons are damaged; 2) the expression of receptors for mediators renin and aldosterone by dendritic cells; 3 ) response to aldosterone through TH17 cell polarization; 4) aldosterone increases the reabsorption of sodium; 5) with the vascular inflammatory mediators, especially cytokines IL-17; 6) increased blood pressure stimulates inflammation so that it becomes an unbroken chain. ${ }^{6,8,15}$ This study did not include patients with hypertension with TDS > 160 mmHg. A study in Fox et al. (2010) included patients with TDS $127 \pm 18 \mathrm{mmHg}$, lower than this study.

Lipid profile of patients with CKD is different from that in healthy people in terms of: 1) HDL does not indicate anti-inflammatory and ateroprotective effects due to uremia; 2) HDL has a decreased function in inhibiting MCP-1, which is important in the process of atherogenesis in vascular smooth muscle cells; 3) LDL has structural and functional changes due to the condition of uremic milieu causing cell dysfunction and tissue damage. ${ }^{7}$ In this study, HDL levels were within normal limits, while LDL levels tend to exceed the normal limits. A study by Fox et al. (2010) included patients with lipid profile with ratio between total cholesterol : HDL by $4.1 \pm 1.3$, not much different from that in this study.

Increased IL-6 in CKD is caused by: 1) chronic oxidative stress; 2) immunity disorder; 3) intestinal barrier dysfunction and endotoxemia; 4) a decrease in cytokine elimination; 5) infection that accompanies CKD; and 6) persistent inflammation that will stimulate systemic inflammation. ${ }^{6,7}$ A study by Pecoits-Filho et al. (2003) supports this, with the average levels of IL-6 was $6.7 \mathrm{pg} / \mathrm{mL}$ for the sample group with eGFR $<6.5$ $\mathrm{ml} / \mathrm{min} / 1.73 \mathrm{~m} 2$ and $4.7 \mathrm{pg} / \mathrm{mL}$ for the sample group with eGFR ? $6.5 \mathrm{ml} / \mathrm{min} / 1.73 \mathrm{~m} 2$. In this study, elevated levels of IL-6 in each group showed no significant difference. In this study IL-6 increased with CKD but could not explain the cause of the increase, possibly because the sample in each group was too small to be analyzed.

\section{Levels of hs-CRP at Each CKD Stage}

Increased CRP is in accordance with the decline in kidney function associated with uremia condition that causes low grade inflammation. ${ }^{6,7,8}$ In this study, the mean hs-CRP levels showed an increase in stage 3 and 4, and mean hs-CRP levels of each group was not much different from those in the study by Fox et al. (2010) who found mean CRP levels of $3.2 \pm 1.1 \mathrm{mg} / \mathrm{L}$. The study by Abraham et al. (2009) found mean hs-CRP in patients with predialysis of $14.3 \pm 11.4$, while the study by Romao et al. (2006) found a mean hs-CRP levels in predialysis patients of $12.1 \pm 13.9$, higher than that in this study. The study by Pecoits-Filho et al. (2003) found a mean hs-CRP levels of $1.14 \mathrm{mg} / \mathrm{L}$ for eGFR $<6.5$ $\mathrm{mL} / \mathrm{min}$, and $0.41 \mathrm{mg} / \mathrm{L}$ for eGFR ? $6.5 \mathrm{~mL} / \mathrm{min}$, lower than this study of $2.29 \pm 2.86$ for stage $3 ; 2.48 \pm 2.19$ for stage 4 ; and $2.09 \pm 2.54$ for stage 5 non-dialysis. CRP native may dissociate into monomeric form under conditions with changes in $\mathrm{pH}$, high urea levels of or low calcium levels. ${ }^{30}$ In this study, mean hsCRP levels, which was a pentameric CRP, increased from stage 3 to stage 4 and then fell on stage 5 non-dialysis.

\section{Comparison of hs-CRP Levels between CKD Stages}

Several studies that explain the relationship betwen decreased kidney function and inflammation are: 1) The study of Pecoits-Filho et al. (2003), which explains that lower LFG is associated with inflammatory conditions due to interference by the renal elimination of proinflammatory cytokines, cytokine production increase in uremia, or other inflammatory effect on renal function; 2) The study by Romao et al. (2006), which explains that patients with CKD have activation of the acute phase response, which is associated with CKD stage; 3) The study by Abraham et al. (2009) who found that there is a high degree of inflammation in patients with predialysis as seen from the high levels of hs-CRP; and 4) The study by Fox et al. (2010) explaining that 
CRP is associated with CKD. In this study there were no significant differences in hs-CRP levels between the CKD stages. Hs-CRP levels in this study did not represent CKD stages due to insufficient sample.

Several theories explaining the relationship between decreased kidney function and inflammation are: 1) reduction in the excretion of proinflammatory cytokines $^{6,14,30}$;2) a decrease in the activity of nitric oxide synthase $^{3,12,19,32}$; 3) decrease in CRP filtration ${ }^{12}$; 4) common risk factors such as hypertension, obesity, and diabetes ${ }^{3,6,12,19,28,32}$; and 5) renal cortical thinning. ${ }^{3,6,12}$ The results of this study could not explain the cause of the increase in CRP because it was not studied. To prove this theory, further research is needed.

Some limitations of the study that could influence the results, among others, is that this study was a crosssectional research so that hs-CRP level examination was only done once, whereas the inflammatory process in CKD was a chronic inflammation. In addition, due to insufficient sample population of patients with CKD in the Kidney-Hypertension Outpatient Clinic, Dr. Soetomo Hospital, majority of the patients were those with stage 3,4 and 5 non-dialysis so that the study could not include stage 1 and 2. The study also did not involve groups of non-CKD patients, and hsCRP levels examined were pentameric CRP, while in the condition of $\mathrm{pH}$ change, uremia, and low calcium levels, it would dissociate into monomeric CRP. Some confounding variables were identified from the history taking, which was very subjective, for example: a history of smoking, sleep disorders, alcohol drinking and drugs taken.

\section{Conclusion}

Distribution of CKD patients in this study were between the age range of $28-65$ years (mean $55.49 \pm 7.62$ years); mostly were female sex; total controlled DM patients were $36.11 \%$, nonDM $63.89 \%$; total hypertensive patients using ACEI/ARB was $43.05 \%$, non-HT/non ACEI/ARB 56.95\%, and total dyslipidemia patients who used statin were $29.16 \%$, non dyslipidemia/non-statin were $70.84 \%$. Mean hs-CRP levels in CKD stage 3 was $2.29 \pm 2.86$; in CKD stage 4 was $2.48 \pm 2.19$; and in CKD stage 5 non-dialysis were $2.09 \pm 2.54$. There was no significant difference between hs-CRP levels in CKD stage 3 , stage 4 and stage 5 non-dialysis. In this study, CRP levels did not represent the increase in CKD stage. Further research must be done on the relationship between hsCRP levels with CKD stage using cohort study and studies similar to this one should involve all stages of CKD (stage 1 to 5).

\section{Conclusion}

The author stated there is no conflict of interest

\section{References}

1. Fasset et al., 2011. Biomarkers in chronic kidney disease: a review. Kidney Int 80: 806-21 doi: 10.1038/ki.2011.198

2. RSDS, 2013. Data penderita penyakit ginjal kronik dan kunjungan hemodialisis di RSUD Dr. Soetomo Surabaya tahun 2008-2012. Sistim Informasi Manajemen RSUD Dr. Soetomo Surabaya, Surabaya

3. López-Novoa JM, Rodriguez-Perla AB, Ortiz A, MartinezSalgado C and Lopez-Hernandez FJ, 2011. 'Etiopathology of chronic tubular, glomerular and renovascular nephropaties: clinical implications'. Journal of Translational Medicine 9:13 doi: 10.1186/1479-5876-9-13

4. Lavin-Gomez BA, Palomar-Fontanet R, Gago-Fraile M, Quintanar-Lartundo JA, Gomez-Palomo E, Gonzalez-Lamuno D, et al., 2011. 'Inflammation markers, chronic kidney disease, and renal replacement therapy'. Advances in Peritoneal Dialysis 27:33-37 PMID: 22073825

5. Kalantar-Zadeh K, 2007. 'Inflammatory marker mania in chronic kidney disease: Pentraxins at the crossroad of universal soldiers of inflammation'. Clinical Journal of The American Society of Nephrology 2:872-875 doi: 10.2215/CJN.02750707

6. Kurts C, Panzer U, Anders HJ and Rees AJ, 2013.'The immune system and kidney disease: basic concepts and clinical implications'. Nature Review Immunology 13:738-753 doi: $10.1038 /$ nri3523

7. Cohen G and Hörl WH, 2012. 'Immune dysfunction in uremiaAn update'. Toxins 4: 962-990 doi: 10.3390/toxins4110962

8. Lacson E and Levin NW, 2004. 'C-reactive protein and EndStage Renal Disease'. Seminars in Dialysis 17: 438-448 PMID: 15660574

9. Autoimmunity Research Foundation, 2012. Test: C-Reactive Protein (CRP), viewed May 14th 2013, <http://mpkb.org/home/tests/crp>

10. Abraham G, Sundaram V, Sundaram V, Mathew M, Leslie N and Sthiah V, 2009. 'C-reactive protein, a valuable predictive marker in chronic kidney disease'. Saudi Journal of Kidney Diseases and Transplantation 20: 811-815 PMID: 19736479

11. Clyne B and Olshaker JS, 1999. 'The C-reactive protein'. Journal of Emerging Medicine 17 (6): 1019-1025 PMID: 10595891

12. Fox ER, Benjamin EJ, Sarpong DF, Nagarajarao H, Taylor JK and Steffes MW, et al, 2010. 'The relation of C-reactive protein to chronic kidney disease in African Americans: the Jackson Heart Study'. BioMed Central of Nephrology 11:1 doi: 10.1186/1471-2369-11-1

13. Romão JE Jr, Haiashi AR, Elias RM, Luders C, Ferraboli R, Castro MC and Abensur H, 2006. 'Positive acute-phase inflammatory markers in different stages of chronic kidney disease'. American Journal of Nephrology 26:59-66 PMID: 16508248

14. Pecoits-Filho R, Heimbürger O, Bárány P, Suliman M, FehrmanEkholm I, Lindholm B and Stenvinkel P, 2003. 'Associations Between Circulating Inflammatory Markers and Residual Renal Function in CRF Patients'. American Journal of Kidney Diseases 41:1212-18 PMID: 12776273

15. Pepys MB and Hirschfield GM, 2003. 'C-reactive protein: a critical update'. Journal of Clinical Investigation 111:1805-1812 doi: 10.1172/JCI200318921

16. Grzegorczyk K, Krajewska M, Weyde W, Jakuszko K, Gniewek A and Klinger M, 2011. 'Gender and kidney disease: the clinical importance and mechanisms of modifying effects'. Postepy Higieny i Medycyny Doswiadczalnej 65:849-57 PMID: 22204762

17. Silbiger S and Neugarten F, 2008.'Gender and human chronic renal disease'. Gender Medicine 5:S3-S10 doi: 10.1016/j.genm.2008.03.002

18. Wang CS and Sun CF, 2009. 'C-Reactive Protein and Malignancy: Clinico-pathological Association and Therapeutic Implication'. Chang Gung Medical Journal 32: 471-82 
19. Savoia C and Schiffrin EL, 2007. 'Reduction of C-reactive protein and the use of anti-hypertensives'. Vascular Health and Risk Management 3:975-83 PMCID: PMC2350124

20. Ridker PM, Rifai N, Pfeffer MA, Sacks F and Braunwald E, 1999.'Long-term effects of pravastatin on plasma concentration of C-reactive protein'. Circulation 100:230-235 PMID: 10411845

21. Icardi A, Paoletti E, Nicola LD, Mazzaferro S, Russo R and Cozzolino M, 2013.'Renal anemia and EPO hyporesponsiveness associated with vitaminD deficiency'. Nephrology Dialysis Transplantation 28(7):1672-79 doi: 10.1093/ndt/gft021

22. KDIGO, 2013. KDIGO 2012 Clinical practice guideline for the evaluation and management of chronic kidney disease. Kidney International Supplements 3: 19-62

23. Leeder SR, Mitchell P, Liew G, Rochtchina E, Smith W, and Wang JJ, 2006.'Low hemoglobin, chronic kidney disease, and risk for coronary heart disease-related death: the blue mountains eye study'. Journal of The American Society of Nephrology 17:279-284 PMID: 16319191

24. Ketteler M, 2011.'Phosphate metabolism in CKD stages 3-5: dietary and pharmacological control'. International Journal of Nephrology 2011:970245 doi: 10.4061/2011/970245

25. Ketteler M, Rix M, Fan S, Pritchard N, Oestergaard O, ChasanTaber S, et al., 2008.'Efficacy and tolerability of sevelamer carbonate in hyperphosphatemic patients who have chronic kidney disease and are not on dialysys'. Clinical Journal of The American Society of Nephrology 3(4):1125-30 doi: 10.2215/CJN.05161107

26. Bargman \& Skorecki, 2008. Chronic kidney disease. In (Faucy AS, Braunwald E, Kasper DL, Hauser SL, Longo DL, Jameson JL, eds). Harrison's principles of internal medicine, 17th edition, USA: McGraw-Hill Companies, Inc, 1761-1775

27. Greenfield JR, Samaras K, Jenkins AB, Kelly PJ, Spector TD, Gallimore JR, et al., 2004. 'Obesity is an Important Determinant of Baseline Serum C-Reactive Protein Concentration in Monozygotic Twins, Independent of Genetics Influences'. Circulation 109: 3022-28 PMID: 15184288

28. Visser M, Bouter LM, McQuillan GM, Wener MH and Harris TB, 1999. 'Elevated C-Reactive Protein Levels in Overweight and Obese Adults'. Journal of American Medical Association 282: 2131-35 PMID: 10591334

29. Schwedler SB, Filep JG, Galle J, Wanner C and Potempa LA, 2006. 'C-reactive protein: a family of proteins to regulate cardiovascular function'. American Journal of Kidney Diseases 47: 212-222 PMID: 16431250

30. Kato S, Chmielewski M, Honda H, Pecoits-Filho R, Matsuo S, Yuzawa Y, et al., 2008.'Aspects of immune dysfunction in endstage renal disease'. Clinical Journal of The American Society of Nephrology 3:1526-33 doi: 10.2215/CJN.00950208

31. Dobrian AC, 2012. 'ADMA and NOS regulation in chronic renal disease: beyond the old rivalry for L-arginine'. Kidney International 81:722-724 doi: 10.1038/ki.2011.496

32. Mugabo Y, Li L and Renier G, 2010. 'The connection between Creactive protein and diabetic vasculopaty. Focus on preclinical findings'. Current Diabetes Reviews 6(1):27-34 PMID: 20034371 